International Journal of Innovative Research and Scientific Studies, 4(1) 2021, pages: 1-13

ISSN: $2617-6548$

\title{
Seismic Response of Multi-Storey Building Using Different Vibration Technique-A Review
}

\author{
Najia Karimi $^{1 *}$, Roozbeh Sarem ${ }^{2}$ \\ ${ }^{1}$ Department of Theoretical Mechanic, Construction Faculty, Jawzjan University, Jawzjan, Afghanistan \\ ${ }^{2}$ Department of Civil Engineering, Construction Faculty, Jawzjan University, Jawzjan, Afghanistan \\ *Corresponding author: Najia Karimi (najiakarimi1986@ gmail.com)
}

\begin{abstract}
This review presents the high performance of failure-resistant structural device system for the sustainable and flexible buildings. Firstly, the motivation and basic principles as well as methodology of the developing device system are explicitly illustrated. Then, the structural detail and seismic response of base isolation systems, namely, lead Rubber Bearing (LRB), HDLRB isolators, viscous damper base isolator (BIPD) and sliding bearing isolator (BISS) are summarized. The theoretical and experimental study results was shown that all four types of isolator system can be able to minimize damage after seismic an earthquake to the structural system. The viscous damper devices and energy dissipate as well as viscoelastic and fluid viscous dampening can be able to enhance the energy dissipation capacity of structural system under an earthquake loading. A placement of L shape, shear walls at the structural configuration plan is given more efficient behavior under seismic load than all other placements of shear walls at the building's configuration. Many numerical specimens of tunnel form buildings were constructed and modelled to analyze and interpreted the dynamic and static cyclic response of structures against seismic force. The deformation of the dynamic response of tunnel form building was smaller by using Carbon Fiber Reinforced Polymer (CFRP) repairing and retrofitting method. Contradictory, the usage of base isolations, energy dissipation devices, shear walls and tunnel form buildings can enhance the efficiency of structures under seismic force by reducing the economic cost saving in their construction.
\end{abstract}

Keywords: Base Isolator, Shear Walls, Tunnel Form Buildings, Passive Energy Dissipates.

DOI: 10.53894 /ijirss.v4i1.49

Funding: This study received no specific financial support.

History: Received: 27 August 2020/Revised: 15 December 2020/Accepted: 5 January 2021/Published: 8 February 2021

Licensed: This work is licensed under a Creative Commons Attribution 4.0 License $\left(\right.$ (c) EY $^{-}$

Acknowledgement: Both authors contributed to the conception and design of the study.

Competing Interests: The authors declare that they have no conflict of interests.

Transparency: The authors confirm that the manuscript is an honest, accurate, and transparent account of the study was reported; that no vital features of the study have been omitted; and that any discrepancies from the study as planned have been explained.

Ethical: This study follows all ethical practices during writing.

\section{Introduction}

Earthquakes are sudden shaking of ground motions which cause based on the fastest release of cumulative energy in the earth's crust. Most of the volcanoes and seismic activity originated from mantle due to high temperature and pressure difference between the crust and the core. Due to this process, many local circulations are produced in different parts of the earth's surface. Most of the population around the world live in high seismic regions. Earthquake is aserious threat to cases structural damages and unlimited loss of the life. If the reinforced concrete buildings are not designed accurately in 
accordance to seismic loading, the buildings may experience completely collapse and severe damages even loss of properties and life [1]. While the earthquake occurs, the structure moves either horizontally or vertically due to the motion of the ground surfaces. Usually, the lateral displacement of the building is much higher than vertical displacement. The performance of the structure under earthquake relevant to the mass, size and configuration of a building or structure and how the structure response under earthquake. Commonly, the buildings with simple rectangular plane configuration and straight elevation stand the best during an earthquake because the inertia forces are transferred without any bend according to the geometry of the building [2]. The structure is designed to hold against the lateral loading induced by earthquake to sustain underground motions. To achieve high seismic resistance of the structure, the resistance system should be able to perform sustain under coming lateral loading during an earthquake [3]. The buildings should have four major abilities which are regular plane shape, stiffness, appropriate lateral strength, and ductility [4]. The predictable design approach was not appropriate to structure to remain totally safe after an earthquake. Over the past couple of decades, a new development an alternative design approach had been made which install the protective system against of the earthquake to the structure [5]. A new strategy has been adopted to induce base isolation in structure to reduce the time period and seismic base shear at the foundation of building [6]. Different isolators and dampers were identified in this literature for structures with or without devices. The main function of isolators and dampers are providing lateral flexibility, energy dissipation and rigidity against of lateral loading [7]. Shear walls and tunnel form building systems are also improving and developing seismic performance of structures against seismic forces [8]. The aim of this review is to verify the efficacy of different isolators, dampers, shear walls and tunnel form buildings seismic performance. The review will explore the possible devices shear walls and tunnel form building in preventing damage and failure in heavy excited motions.

\section{Structural Vibration Control Method}

Ordinarily, earthquake and wind load produce vibration and lateral displacements to the structures [9]. Vibration of the structures can be controlled and reduced by various fundamental systems, including modifying damping, mass or shape, passive and active dampers dissipate, active control, seismic-active control and, hybrid technique [10]. Passive devices have their own energy to direct response against the motion of the structure [11]. While active devices require external power sources to equip extra force to the building in an advised method. By using the actuator, the signals are sent through, to control the actuator and calculate the feedback from the sensors provided on the structure. The forced to apply by the exterior power source, then, will add or dissipates the energy from the superstructure to the substructure. The function of the Seismic-control is beneficial on the active dampers and reliable for passive energy controls. Specifically, seismic control performs similar principle with active dampers and requires small external energy. In another view, hybrid control technique is performed with using combined principles of active and passive energy dissipates. Therefore, the structure which equipped with a base isolation system, shear walls, tunnel form buildings and passive and active energy dissipates will experience less vibration and damages under earthquake excitations.

\subsection{Base Isolation System}

Nowadays, based isolation system is a unique and popular device for seismic resistant and design of buildings around the world. Many researchers had done numerous important studies on the base isolation system, which has been completely admitted in the engineering field. A full-scale shaking table test was done to test the different types of different isolators [13]. Seismic load and wind load are the most major loads that cause the lateral movement design of the building. Therefore, seismic load cannot easily control and practical design a building under an unlimited earthquake load [14]. This system is one of the main passive energy dissipation technique for seismic occurrence regions. It is useful to control and reduce the amount of the energy which comes from the ground to the upper stories of the structure. It is also useful to control the energy which passes from the foundation or ground to the higher stories. For achieving the flexible layer of isolator the base isolation system has to be installed or located between the superstructure and substructure [14]. The system will reduce the dynamic main parameters of vibration such as fundamental natural time period and frequency at ultimately. Likewise, the resonance situation between the ground acceleration and structural vibration will avoid automatically [15].

The main usage of a base isolation system is to minimize the lateral deformation, base shear and member forces in the structural system [13]. There are different types of isolation systems, namely rubber bearings and friction bearings. The rubber bearing isolators and frictional isolators are classified into subtypes of isolates according to the components of the material and functions of the devices. The usage of base isolation system depends on its rigidity and the content of energy dissipation. Therefore, the isolator system must be a single unit to increase natural time period of structure effectively and reduce the response of building against seismic load [14].

Figure 1 (a) and (b) shows the lead rubber bearing isolation system. This system is one of the main effective bearing which gives lateral flexibility to the building. The performance of the building during an earthquake depends on the category, specifications and function of base isolation systems.

The simple friction isolator system is comprised of large deformation on its surface mechanism. The best performance of friction sliding bearing isolator could be achieved by introducing any recovering mechanism. For example, the middle and the outer rubber cores in flexibility friction bearings provides in restoring mechanism as shown in Figure 2 (a), (b) and (c) $[12]$. 


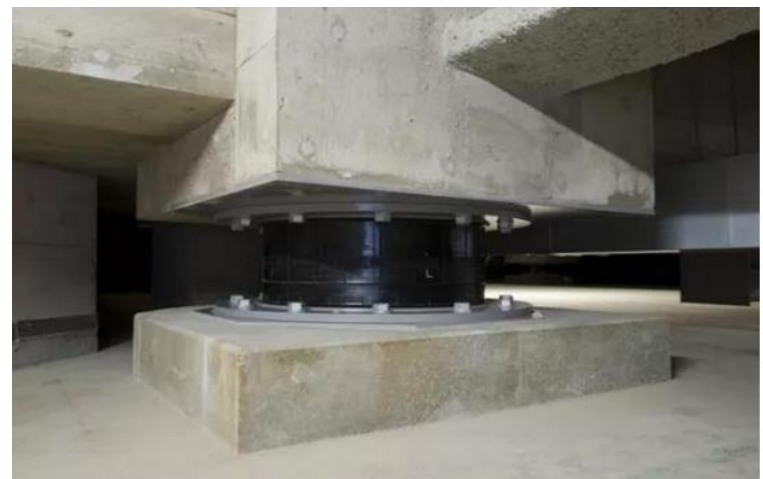

(a)

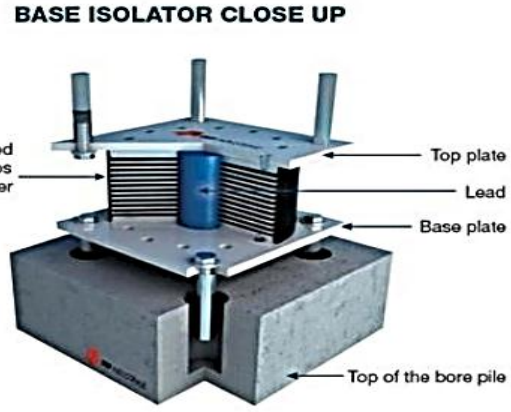

(b)

Figure-1.

(a) Lead rubber bearing base isolation and (b) components of laminated Rubber bearing isolator [12].

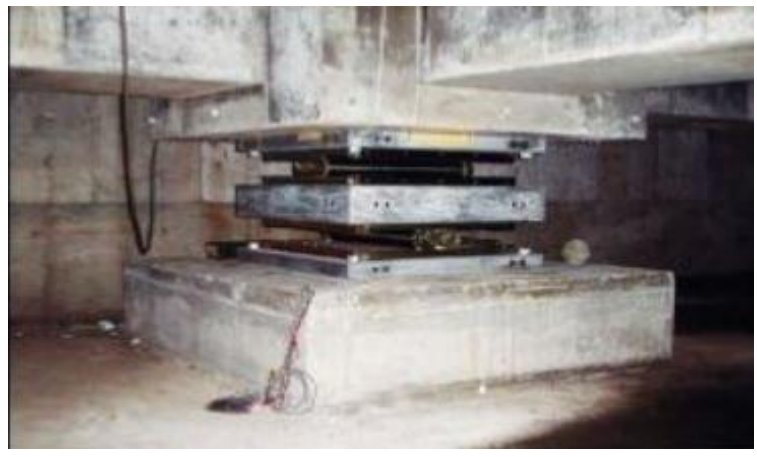

(a)

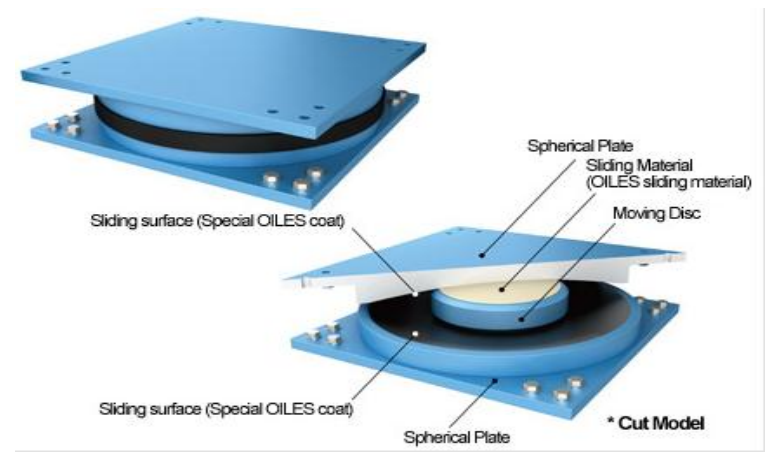

(b)

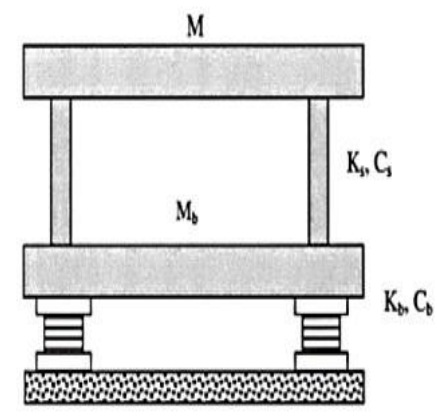

(c)

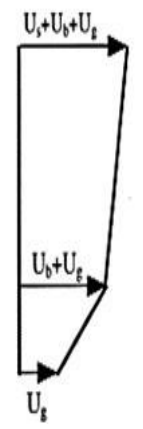

Figure-2.

(a) Sliding base isolator foundation, (b) components of sliding base isolated devices and (c) a rigid body siting on a flexibly bearings [16, 17].

The equation of motion for the building which equipped with base isolation system can be calculated using Equation 1.

$$
m \ddot{u}_{s}+c \dot{u}_{s}+k \dot{u}_{s}=-m\left(\ddot{u_{g}}+\ddot{u_{b}}\right)
$$

For the buildings which build using fixed foundations, the natural time period and frequency can be expressed in Equation. 2.

$$
W_{f}=\sqrt{\frac{k}{m}} \quad T_{f}=\frac{2 \Pi}{\omega_{f}}
$$

By introducing the stiffness and damping inside the layer of isolation into the fixed base of the building. The natural frequency and time period can be gotten as a below (Equation 3).

$$
\omega_{b}=\sqrt{\frac{k_{b}}{m+m_{b}}} T_{b}=\frac{2 \Pi}{\omega_{b}} \quad \xi_{b}=\frac{c_{b}}{2\left(m+m_{b}\right)} \omega_{b}
$$




\subsection{Shear Wall}

Shear wall of reinforced concrete buildings commonly design to carry seismic, wind and gravity loads. The construction of shear walls starts from the foundation throughout to the height of the building. However, However, shear walls provide higher stiffness and strength to buildings in the direction of their orientation which significantly reduce lateral displacement and structural components failure against of seismic loading [18]. Shear walls in the buildings should be placed symmetrically in plane against of the twisting effect in buildings. This system must be inverted symmetrically in plane either in one or two directions [17]. Lateral load bearing shear walls are more effective when located along exterior perimeter of the building. The symmetrical plane configuration enhances the seismic response of the building against of earthquake loading. Door and window openings could be provided to the shear walls, but their size openings should be small and located symmetrically to experience least interruption to force flow through of walls. A symmetrical arrangement of door and window openings could make the performance of the shear walls become more effective [18].The shear walls can be placed in-plane; open-sections and closed-sections. A common shape of shear wall is the rectangular section mostly L-shape and $U$ shape are used for cross section of shear wall for construction of medium to high rise buildings which frequently constructed on repetitive cellular unlimited plans [19]. Shear walls commonly used for construction of multi-storey residential houses, apartment buildings and condominiums to strengthen the behavior of structures under lateral loading as well. The simultaneous casting of walls and slabs in monolithic are different from any other frame type of RC buildings. RC shear walls are normally used in multi-storey buildings. RC shear walls act as vertical cantilevers, will provide a good lateral suitability, performance to resist the horizontal external forces. In addition, an optimum stiffness and strength ductility could also be achieved by installing the shear walls (Figure 3(a) and (b)) [19].

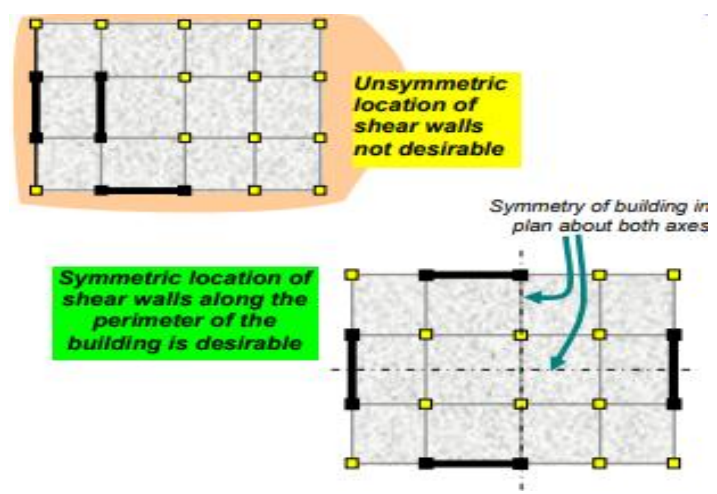

(a)

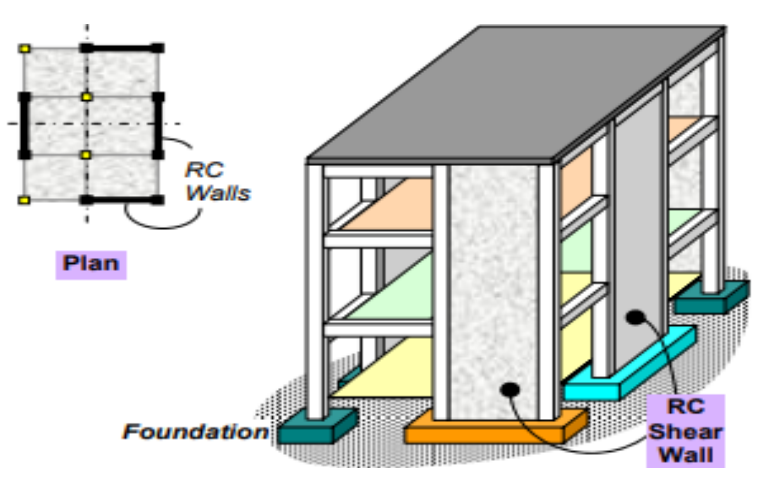

(b)

Figure-3.

(a) Symmetric and asymmetric locations of shear wall and (b) different locations of shear wall [20].

\subsection{Tunnel Form Building}

Tunnel form building system was developed more than 50 years ago in high seismic regions worldwide. Its commonly utilized to construct cellular and repetitive form, medium and high-rise structures in one daily cycles. This system is usually identified as a modern construction technique to construct slab and RC shear walls in monolith system [21]. It has been used by developers and contractors because of the low cost in construction, high quality product and earthquake resistance. This type of structure usually used for construction of multi-storey domestic units. The load carrying mechanism of this system is comprised of composing RC slabs and shear walls only. Tunnel form building construction method is gained faster constructed, good quality product, reduce the manpower, formwork, cost saving and provide best earthquake resistance as compared to the conventional method. This technique is extremely regular, seismic the manpower, formwork, cost saving and provide best earthquake resistance as compared to the conventional method. This technique is extremely regular, seismic resistance that provides normally the uniform architectural structural configurations. Recently, tunnel form buildings are designed and constructed without beams and columns with composed of RC slabs and shear walls as a good load carrying and transferring mechanism. Currently, tunnel form building construction is proven quite attractive rather than conventional approaches as shown in Figure 4. 


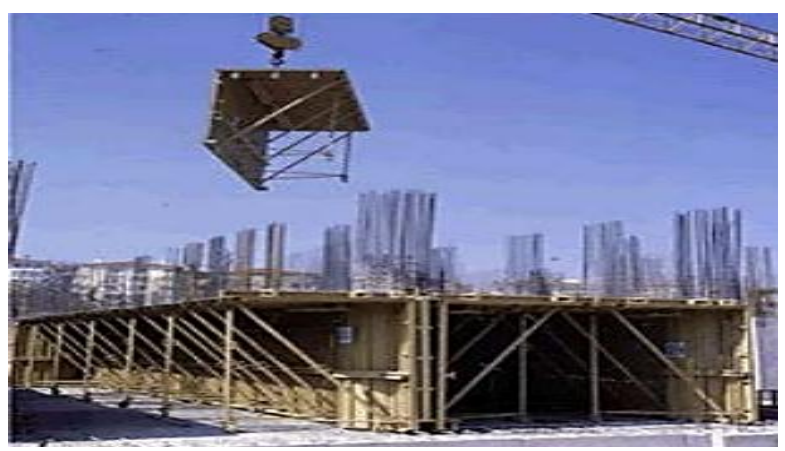

Figure- 4.

Formwork of tunnel form building [21].

Its speedy construction method including good quality, exactitude, cost saving in finishing work at high seismic risk popularity [22]. During construction of this system the reinforced concrete slabs and shear walls are cast at a similar thickness of thin layer of concrete plate and, the reinforced bars should be placed in one layer [22]. Tunnel form building can enhance the seismic behavior of building by delaying the plastic hinge formations at slab wall connections and around wall openings which the most critical locations as shown in Figure 5.

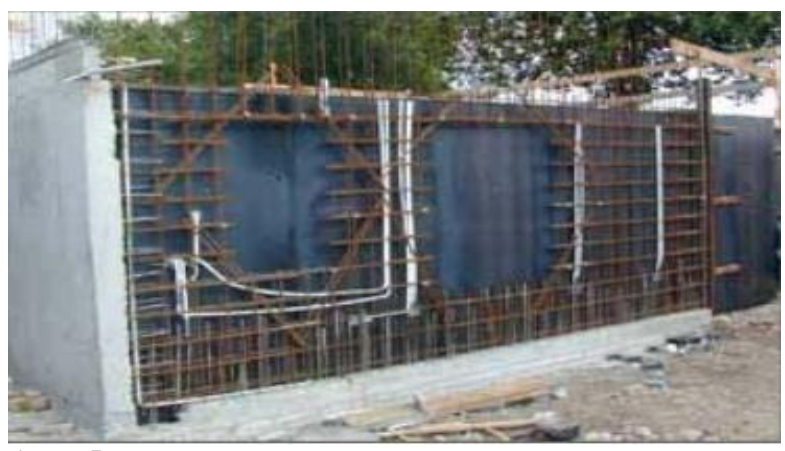

\section{Figure-5.}

Reinforced details of shear walls with and without openings [21].

\subsection{Damping}

In seismic regions, dampers are installed in the structures for upgrading the seismic performance and reduction of lateral force during an earthquake. The installation of damping, fortunately, could reduce the vibration, overturning a kinetic energy of the structure [23].

The dampers which are passive energy dissipation devices will reduce the acceleration and displacement reaction of the building hence decrease the natural frequency of the structure close to zero. The types of dampers are categorized based on the characteristic of materials and functions to friction, metal (fluid), viscous, viscoelastic; shape memory alloys and mass dampers [24]. However, easy to install and replace the dampers as well as its coordination to other structural members and have to be taken into consideration when dealing with high kinetic energy.

The efficiency of the dampers is depended on the loading velocity and ambient temperature as well. Based on the simplicity of installation, stability and coordination with other members also and variety of sizes, viscous dampers have numerous applications in designing and retrofitting. For example, friction dampers. Friction dampers are designed to overcome the friction due to the seismic energy on the contact surfaces [25]. The installation of dampers in parallel to the bracing is shown in Figure 6 (a). The usage of viscous damping fluid inside a cylinder will dissipate the energy to the structures as shown in Figure 6 (b).

The governing differential equation of motion for multi degree of freedom can get by using Newton's Second law in Eq. 4.

$$
m_{1} \ddot{x}_{1}+c_{1} x_{1}+k_{1} x_{1}-k_{2}\left(x_{2}-x_{1}\right)-c_{2}\left(x_{2}-x_{1}\right)=0
$$



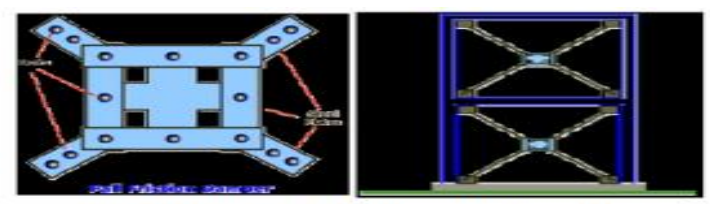

Fig. 7: Using Pall friction dampers[12].

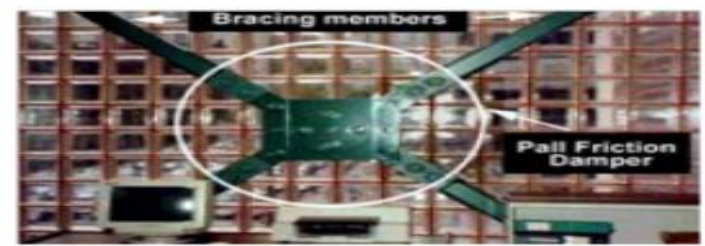

(a)
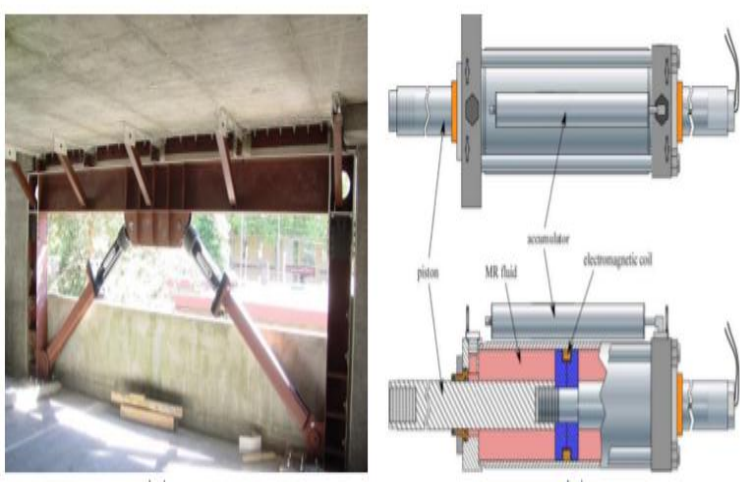

(b)

Figure-6.

Pall friction damper and (b) Viscouse fluid damper [12, 17].

\section{Review of the Previous Studies}

Recent studies on a base isolation system, shear wall, tunnel form building, and passive dampers are mainly focusing on design parameters, modification factors, failure mechanisms, strength, repairing, and retrofitting techniques of buildings against the earthquake load. Comparative studies between base isolation system, shear wall, tunnel form building and passive dampers are also found to be reviewed. Javadian, et al. [26] studied on adopting the process of base isolation system in the development of three-storey building. Due to the regular geometrical plan of the building, similar spacing of reinforcement bars in both directions and poor ground conditions influence also was added to the attraction of using base isolation system. The structure with base isolated system was designed and modelled using SAP2000 software. A base isolated system was stated in this study to provide the most economic design and the highest content protection for threestorey building. The detailing of design carried out based on the non-linear time history analysis. A lead rubber bearing system was installed to the based isolation. As a result, the initial investigations verified $65 \%$ reduction in the seismic base shear of the structure as well as up to $90 \%$ reduction in floor accelerations at data hall level, could be achieved. The propose of base isolation systems has provided in approximately $35 \%$ reduction in the construction cost of the building's foundation. This system reduced the cost saving of the construction from pilling process and bracing installation [26]. Mosbeh-Kaloop and Wan-Hu [27] utilized the modern application advanced soft computing technique to expect the seismic response of the centrically bracing frame system with lead rubber bearing (LRB) base isolation under eight past earthquake records. The methods were included of lest square support vector machine (LSSVM), wavelet neural, network (WNN) and adaptive neuro fuzzy inference system (ANFIS) along with (wavelet thresholding) which transforms concentrates and images, appearances in a few large-magnitude wavelet coefficients. The comparison of 2D frame under eight numbers of past ground motion records was done to evaluate and estimate the production response of 2D frame models. From the simulated results the least square support vector machine is proved an excellent technique than other techniques in estimating the earthquake behavior of smart structures [27].

Ma, et al. [28] compared the stochastic behavior of high-rise buildings with a base isolated system which, completely subjected under different earthquake excitations. The combination of pseudo excitation and the equivalent linearization techniques and the results achieved by the pseudo excitation was investigated by the Monte Carlo technique. The high- rise building with base isolated system was presented using finite element models and a multi-degree of freedom shear model respectively. The effect on the models and numbers of mode shapes of superstructure participating in determining the seismic response of a base isolated system. The results obtained from a 20-storey, 3D-frame model with the similar height to width ratio 4 indicate that storey drifts and absolute accelerations of the high-rise building has been estimated accurately while a multi-degree of freedom shear-type model was utilized to neglect the higher modes of high-rise building. Eventually, this system has no impact in the drift of the base slab [28].

Pan, et al. [29] focused on the developmental history and usage of base isolated systems and energy dissipates for structural systems in China. Major findings were proved the standardization of basic design procedures over ten years of experiences, that mostly considered and determined the seismic design forces, selection of earthquake excitations, modeling process, time-history analyses, and performance criteria. The nonlinear time-history analyses were done under various ground motions characteristic of the base isolated and energy dissipation structural systems. Better quality control and standardization of devices will balance between performance and economical cost of the building. The regulations, standardization and quality control of devices, balance between performance and economical cost, comparison of real response and theory inspections were predictable as the issues that must be improved to further promote the application of base isolation system and energy dissipations for structures in China [29].

Sunita and Ajay [30] compared the seismic behavior of a fixed base structure with a base isolated structure and parametric base isolation systems. A three storey reinforced concrete structure was recognized for dynamic response analysis as a shear typed building with one degree of freedom at each floor. The base isolation systems were used in this study, namely, Laminate Rubber bearing (LRB), Lead Rubber Bearing (N-Z bearing) and friction Pendulum system (FPS). The dynamic behavior of structure with fixed base isolation were evaluated according to the maximum inter- storey drift, maximum acceleration at top floor, lateral displacement. The parameters were evaluated for based isolation system are (1) 
time period and damping factor for LRB isolator system (2) natural time period, yield strength capacity and damping coefficient for N-Z bearing isolator system (3) time period and friction coefficient for FPS. The results illustrated that the base isolation system is very effective in reducing seismic behavior of building and parametric base isolation system also influence significantly the seismic behavior of a base isolated building [30].

Fabio [31] performed the non-liner seismic behavior of a five storey typical framed structure with various bases isolated system. The HDLRB-types of base isolation compared with the base isolations with viscous dampers acting parallel and sliding bearings isolators with steel PTFE additions acting either parallel or sequentially. The various values of parameters characterized the seismic behavior of devices as well. The results found that the base isolations with in parallel arrangements of viscous dampers as well as the sliding bearings isolators are able to control the displacement of the structure respectively. The increment of equivalent damping $(\xi D)$, and the sliding ration $(\alpha S)$ have represented the displacement reduction of the (BIPD) base isolators. In case, the re-placing of this system after an earthquake is required while the flexible restoring force created by the elastomeric isolators should not exceed the friction forced by the sliding bearings. Usually, combinations of isolators and sliding bearings (BISS) are not satisfied enough for increasing of $\alpha \mathrm{S}$ parameter and reducing the remaining displacement of base isolation system. Thus, by replacing of this system may produce some difficulties when the remaining displacement is a combination of out-of-phase movements between the isolators and the sliding bearings placed on them [31].

Lavanya and Manjunatha [32] dealt with the influence of fluid viscous and viscoelastic dampers in RC reinforced concrete buildings. Based on the IS 2002 seismic design, code, the structures were analyzed according to the static and dynamic response spectrum analysis method. The modelling and analysis were done using SAP 2000 program. The seismic performance of buildings was evaluated in terms of the natural time period, frequency, horizontal displacement, base shear force and storey drift of buildings. The comparison had been made between the structures with dampers and without dampers. The outcomes indicated that the fundamental natural time period of the building decreased about $53 \%$ by using viscoelastic dampers. While, the natural time period of the building was reduced of about $56 \%$ by using the viscous dampers. After the installation of viscoelastic, the base shear force of the building was increase and fluid viscous dampers as compared to the buildings without dampers. Eventually, the fluid viscous dampers were effectively reducing the lateral displacement of the building about $65 \%$ to $70 \%$. The viscoelastic dampers were also effectively reducing the lateral displacement of the building of about $55 \%$ to $60 \%$. In addition, the installation of viscous dampers to the building had also decreased the percentage drift of the building of about $70 \%$ to $75 \%$ when compared to the percentage drift given by viscoelastic dampers to the building [32].

Usha and Prabhakara [33] preformed the seismic behavior influence of multi-storey buildings with the addition of friction dampers. According to the IS 2002 design codes of practice, the analysis was done using an equivalent static method, response spectrum and time history analysis method. The multi-storey structure was modelled and using SAP 2000 program. The outcomes of the seismic behavior of multi-storey building were determined in terms of time period, base shear force, horizontal displacement and percentage inter storey drift. The comparison between the structure with friction dampers and without dumpers was also evaluated in according to the fundamental time period, base shear, lateral displacement and percentage drift. From the obtained results, the lateral displacement of the building was reduced by installing of friction dampers to the building. similarly, the storey drift of the building also reduced as well, but the shear resistance of the building was increased alternatively [33].

Sanghai and Pawade [34] concerned about the influence of placement and number of friction dampers on seismic behavior of 2D framed buildings. The two bays \& five- storey 2D frame structures were analyzed and interpreted using SAP 2000 software. Four numbers of friction dampers were provided at different plane location of the building to ensure the slip load \& stiffness remained constant. As the behavior of friction damper is an elasto-plastic model, the none-linear Time History Analysis of all frames were recorded using 1940 El Centro ground motion past record. The effect of number and position, percentage energy dissipated in accordance with energy induced in the frame had been analyzed and interpreted according to the natural time period, horizontal displacement, base shear force, joint deformation and member forces. The results showed that the number and placement of damper influenced significantly the structural response of 2D frame structures. A large number of dampers do not always lead to the best benefit in terms of energy dissipation. Instead of that, the location of dampers had tuned the building with respect to increase the acceleration dissipates at maximum percentage of input energy [34].

Sharmin, et al. [35] explored the finite element analysis and modelling response of reinforced concrete shear wall building with opening gaps under seismic loading. Nowadays, RC shear walls commonly used in high-rise buildings as a vertical member to resist horizontal loading which produces by wind and earthquake load. Normally, the RC shear walls which placed at the sides of the structures or positioned in the form of openings that houses are stairs and lifts. In most of the buildings dimension and positions of the cores in RC shear walls are considered without effective seismic response of the structure. The study carried out on six storeys framed reinforced shear walls for linear analysis of the structure using ETABS program. The outcomes indicated that the stiffness of the building and seismic behavior of the building affected by the opening of the shear wall as well as the positions of the RC shear walls. Furthermore, it was found also the lateral drift able to reduce by taking of the elements of concrete shear walls around opening areas [35].

Anshul, et al. [36] preformed seismic behavior of a five storey reinforced concrete building by considering of four numbers of shear walls configurations. Five various shear wall configuration plane was considered in this study, shear walls symmetrically was placed in exterior bays, corner and adjusting positioned on the exterior bays of the building. The seismic analysis of these RC frame buildings was evaluated based on the inter-storey drift, member forces, base shear force, and joint deformations. The building with different placements of shear walls at the corner and centrally at exterior 
bays indicates the minimize of more than $29 \%$ to $83 \%$ in horizontal deformation. In interior and perimeter columns the bending moments ratios are decreased almost $70 \%$ to $85 \%$ similarly, shear force and axial forces in columns also minimized about $86 \%$ and $45 \%$ respectively. From the results, the best location of shear walls at the configuration of buildings plane proposed [36].

Gawady and Shingadi [37] compared the seismic behavior of different placement configuration of shear walls in terms of inter-storey drift, member shear forces, deflection, hinges formation, natural time period and etc under lateral loading. According to the linear and non-liner seismic analysis of the structure, the position effect of shear walls was compared in terms of parameters mentioned. A push over analysis was used to estimate the seismic performance of the building by considering the strength and displacement demands of the structure. To estimate the seismic performance of the building the spectrum method was used in ETABS software Gawady and Shingadi [37]. Varsha [38] Explored on RC reinforced six-storey concrete building located in Nagpur India exposed to seismic loading in zone-II. The seismic load was computed using the seismic coefficient technique in accordance to IS 1893 (PART-I):2002. The design and seismic analysis were done in STAAD Pro V8i program. The study was done to calculate the capability of concrete shear walls of a multi-storey building by exchanging shear wall positions in the architectural plane configuration of building. According to the seismic coefficient method three numbers of different cases of shear wall positions for a six storey building were analyzed. The conjunction of shear wall was unavoidable in multi-storey structure to resist the horizontal loading. Conclusively, it was found that the placement of the L shaped shear wall was more efficient against of lateral displacement of the building than all other types of shear wall [38].

Balkaya and Kalkan [39] Performed the seismic performance of tunnel form buildings using nonlinear pushover analyses for two buildings using 3D and 2D programming. The results found out that the total resistance capacities of 3D structures had a higher value than 2D modelled structures [39]. They explored the dynamic characteristics of shear-wall structure constructed using tunnel form building techniques. A total 80 number of different structural conformations, were evaluated using 3D finite-element modeling and a set of new experimental equations. The outcomes discovered that the given formula comprising new parameters has given a correct prediction for the broad range of various architectural configurations, roof heights and shear wall distribution. This could be an effective device for the implicit design of the buildings Balkaya and Kalkan [39]. Balkaya and Kalkan [39] proposed the response modification factor (R-factor) which generally intended to account the period of the tunnel form building system. The value of R-factor can be obtained by multiplying R $\mu$ by RS and RR Balkaya and Kalkan [39]. Kalkan and Yüksel [40] Conducted the strengthen and weakness of the tunnel form structures in terms of design expectations and constructions requirements. The effects of shear wall detailing reinforcement ratio, ductility load bearing capability and failure mechanism were evaluated under loads at section and global system levels. The experimental results indicated that the reinforced concrete shear walls of tunnel form buildings with low axial pressure ability represent inelastic soft failure under lateral seismic load. The inelastic failure was placed due to breaking in longitudinal reinforcement with no shrinking of concrete Kalkan and Yüksel [40]. Tabassum and Ahmed [23] presented that the current seismic design codes of practice and procedures do not provide strong enough requirements for seismic design of tunnel form building system. Most of the designers invented the modern force-based design method to design tunnel form building system. The finding was proposed that the natural time period (T) and the response factor ( $\mathrm{R}$ factor) had been used in the design-based shear. As a result, the natural time period and mode shapes of tunnel form buildings were behaved linear response to each other. The study also presented that the height of the building can play major role as the main parameter to estimate the natural time period of the tunnel form building system Tavafoghi and Eshghi [41]. Eshghi and Tavafoghi [42] conducted an empirical work on seismic behavior of tunnel form building system. The two specimens of three-storey tunnel form building with one fifth scale had been designed, constructed and tested under quasi-static lateral cyclic loading, to evaluate the fundamental natural time period and mode shapes of cracked structures. The numerical simulated results found best relationship in the evaluation of fist mode shape in X-direction, however the estimated period in Y-direction and torsional mode had some differences with empirical results Eshghi and Tavafoghi [42]. Hamid and Masrom [43] computed the seismic response of tunnel form building system according to the parameters as lateral strength capacity, stiffness, hysteresis loops, ductility, damage states and modes of failure. The wallslab joint region was evaluated over to failure drift of $2.5 \%$. The equations were amended to compute ductility and moment resistance of wall section joint region theoretically. During pushing in out-of- plane direction the spalling of concrete was observed at the upper parts of the joints and cracking of longitudinal reinforcement bar in the wall panel was occurring. The theoretical and experimental results compared and it indicates a good correlation between them Hamid, et al. [44]. Hamid, et al. [44] adopted the technique of repairing and strengthening for single unit three-storey tunnel form building which experienced under in-plane lateral cyclic loading. The combination of steel angle, steel plate and Carbon Fiber Reinforce Polymer (CFRP) fabric methods were utilized for strengthening tunnel form building system. The CFRP fabric method was used to wrap the shear walls and prevented the concrete walls from easily falling out and crash during an earthquake occurrence see (Figure 7) [44]. 

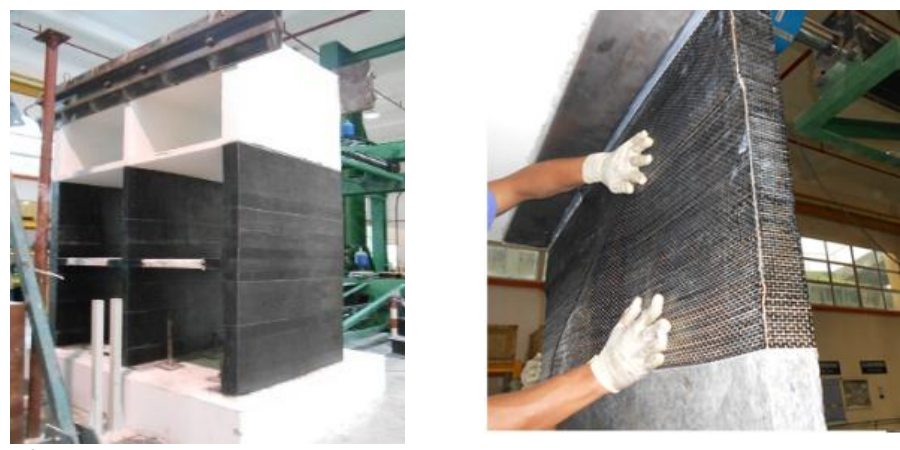

Figure-7.

Wrapping of CFRP around of shear walls [44, 45].

Hamid and Anuar [46] Experienced the seismic behavior of one-third scale of double units, three- storey tunnel form reinforced concrete structure under in-plane lateral cyclic loading. The structure, designed and constructed in the laboratory based on the BS8110 code and using displacement method. The results showed that the maximum values of lateral strength $93 \mathrm{kN}$, maximum displacement ductility 2.5 , average elastic stiffness $6.11 \mathrm{kN} / \mathrm{mm}$, and average secant stiffness $2.94 \mathrm{kN} / \mathrm{mm}$ at the in plane direction. Similarly, the equivalent viscous damping (EVD) also estimated at $15 \%$ and $6 \%$ for first and second cycles correspondingly [46].

Hamid and Anuar [46] constructed single and double units, three-storey tunnel form building system in laboratory and evaluated under in-plane and out-of-plane lateral cyclic loading. The cracked buildings were repaired and retrofitted by using steel channel, steel angle, CFRP and enlargement of the external walls. The repaired and retrofitted spacemen were modelled using the RUAUMOKO 2D program. The experiment results showed the highest values of lateral strength capacity, ductility, stiffness, and equivalent viscous damping of the repaired and retrofitted specimens than the unrepaired specimens. The results have proven that there was a good correlation between the empirical and modeling hysteresis loops using Ruaumoko 2D program as shown in Figure 8 [45].

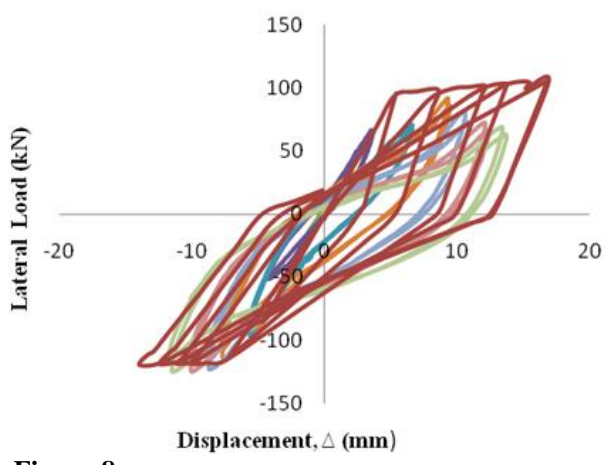

Figure-8.

Comparison hysteresis loops between experimental and modeling [45].

\section{Discussion}

The stiffness and martials used for developing of based isolation and damper devices are very important issue to be considered, while other factors such as buildings configuration plans, height of the building and ground motions also play major roles on the seismic performance of the buildings against of seismic load. The trend of using of base isolation, dampers, shear walls and tunnel form building system in structures had been changed from the past decades. By adopting of different types of based isolation and energy dissipation devices can be able to reduce the structural damage under seismic force. In addition, by using of shear walls at the buildings configuration plan and tunnel form building construction method can save the twisting and collapse of structural components under past ground motions. However, from the past reviews lead rubber bearing isolator can be able to reduce around $35 \%$ cost construction of the building's foundation while usage of viscous damper reduces 70 to $75 \%$ drift of the building against of seismic force. Moreover, shear walls and tunnel form buildings technique could decrease the construction cost of the buildings about $20 \%$ as compared to the conventional buildings.

\section{Conclusions}

Earthquakes are a serious threat to damage of structures in the high seismic regions around the world. Based on the past literature reviews of the basing isolation system, damper, shear wall and tunnel form building. It is noticed that, the using of these systems for structures and infrastructures are increasing yearly in countries that involve lots of earthquake activates such as China, Japan, Turkey, Malaysia, India and other parts of the world which located in pacific "Ring of Fire". Many researchers had done numerous research regrading based isolation system, dampers, shear walls and tunnel form buildings. But the methodology and results obtained still discussed not clearly clarify. For non-seismic regions using of base isolation and dampers are still nominal due to the cost of construction and maintenance of devices, however shear walls and tunnel form buildings generally used to construct high rise wind load resisting buildings. The work mainly 
focuses on base isolation, dampers shear walls and tunnel form buildings to enhance seismic performance. LRB Lead Rubber Bearing with an addition of least square support vector machine is superior to other techniques in estimating behavior of the structure. Base isolation with in-parallel combination of dampers as well as sliding barring can be able to control the displacement of structure respectively, however the re-centering and replacing of this system may produce some difficulty in remaining displacement. Viscous damper decreases the percentage drift of the building about $70 \%$ to $75 \%$ when compared to the percentage drift given by viscoelastic dampers to the building. Placement of shear walls at corner and centrally at exterior bays of the building configuration indicates attractive reduction up to $29 \%$ to $83 \%$ in lateral displacement. Moreover, L shaped placement of shear walls were more efficient against of lateral displacement of the building than all other types of shear wall. Many methods of repairing and retrofitting were used for strengthening of tunnel form building in the laboratory, which are steel channel, steel plate, enlargements of column and CFRP. However, the best method is CFRP (Carbon Fiber Reinforced Polymer) to increase time period thus reducing seismic vibrations in tunnel form building system. The good relationship was found between experimental and modelling parameters by using Ruaumoko 2D program. The findings also showed that the height of the building can be considered as the main parameter in estimating the fundamental time period of the tunnel form building and 3D models has higher resistant capacity than the 2D model structures. The review will explore the potential of base isolations, dampers, shear walls and tunnel form buildings in improving the seismic performance of buildings, in civil infrastructure and designs.

\section{References}

[1] T. A. Adagunodo and L. A. Sunmonu, "Earthquake: A terrifying of all natural phenomena," Journal of Advances in Biological and Basic Research, vol. 1, pp. 4-11, 2015.

[2] R. Murty, A. R. Vijayanarayanan, and V. Mehta, Earthquake behaviour of buildings. Gujrat State: Disaster Management Authority, 2012.

[3] S. D. Parekar and D. Datta, "Seismic behaviour of stiffness irregular steel frames under mainshock-aftershock," Asian Journal of Civil Engineering . vol. 21, pp. 857-870, 2020. Available at: https://doi.org/10.1007/s42107-020-00245-z.

[4] Y. Alashker, S. Nazar, and M. Ismaiel, "Effects of building configuration on seismic performance of RC buildings by pushover analysis," Open Journal of Civil Engineering, vol. 5, pp. 203-213, 2015. Available at: https://doi.org/10.4236/ojce.2015.52020.

[5] Y. Nakumura and K. Okada, "Review on base isolation and response control methods of buildings in Japan," Environmental Disaster, vol. 6, pp. 1-10, 2019. Available at: https://doi.org/10.1186/s40677-019-0123-y.

[6] N. Makris, "Seismic isolation: Early history," Earthquake Engineering \& Structural Dynamics, vol. 48, pp. 269-283, 2019. Available at: https://doi.org/10.1002/eqe.3124.

[7] M. Ismail, "An isolation system for limited seismic gaps in near-fault zones," Earthquake Engineering \& Structural Dynamics, vol. 44, pp. 1115-1137, 2015. Available at: https://doi.org/10.1002/eqe.2504.

[8] L. Jianbao, F. Qioqiao, L. Zheng, and Y. Young, "Experimental study on seismic performance of T-shaped partly precast reinforced concrete shear wall with grouting sleeves," The Structural Design of Tall and Special Buildings, vol. 28, p. e1632, 2019. Available at: https://doi.org/10.1002/tal.1632.

[9] Azlan and Adnan, "Comparison on the effect of earthquake and wind loads on the performance of reinforced concrete buildings," presented at the 14th World Conference on Earthquake Engineering October 12-17, Bijing China, 2008.

[10] A. Jorge, Cortes-Ramirez, and M. Martinez, "Characterization, modelling and simulation of Magnetorheological damper behavior under triangular excitation," Mechatronic for Safety, Security Dependability in a new era, 2007.

[11] V. Chachpara, P. V. Patel, and S. P. Purhit, "Seismic response control of the buildings passive devices," presented at the International Conference on Current Trends in Technology, 2011.

[12] S. Nath and S. Nirmalendu, "Methods for improving the seismic performance of structure-A review," presented at the International Conference on Mechanical, Materials and Renewal Energy, 2018.

[13] M. Jain and S. Sanghai, "A review: On base isolation system," IJSART, vol. 3, pp. 326-330, 2017.

[14] V. Aparna and G. Ashutosh, "On base isolation system," International Journal of Engineering Science Innovation, pp. 43-46, 2017.

[15] N. Torunbalci, "Seismic isolation and energy dissipating systems in earthquake resistant design," presented at the In 13th World Conference on Earthquake Engineering, 2004.

[16] N. Koji and W. Naoya, "Development of spherical sliding baring," Nippon Steel \& Sumitomo Metal Technical Report No, vol. 115, pp. 62-531, 2017.

[17] T. Chieh-Wu, "Design of base isolation system for buildings," Master Thesis, Massachusetts Institute Technology, 2001.

[18] K. S. Sruthy and J. D. C. Justine, "Effect of opening on reinforced concrete coupled shear wall," International Journal of Scientific \& Engineering Research, 2017.

[19] S. Shiva and P. Sunil, "A study on construction of rc shear walls for multi-storied residential building," International Journal for Research in Applied Science \& Engineering Technology, 2017.

[20] M. Renu and A. K. Dawivedi, "Symmetrically and non-symmetrically pattern of shear walls," International Journal for Innovative Research in Science \& Technology, pp. 2349-6010, 2016.

[21] Y. Ahmet and G. Polat, "Housing report Tunnel form building," World Housing Encylopedia, EERI Report, No 1012003.

[22] Q. U. Z. Khan, A. Ahmad, F. Tahir, and M. A. Iqbal, "Effect of shape of shear wall on performance of mid-rise buildings under seismic loading," Technical journal, University of Engineering and Technology (UET) Taxila, Pakistan, vol. 21, p. 31, 2016.

[23] T. Tabassum and K. S. Ahmed, "Seismic performance of damper installed in high-rise steel building in bangladesh," Journal of Civil Engineering, Science and Technology, vol. 9, pp. 1-12, 2018. Available at: https://doi.org/10.33736/jcest.876.2018.

[24] A. Ras and N. Boumechra, "Seismic energy dissipation study of linear fluid viscous dampers in steel structure design," Alexandria Engineering Journal, vol. 55, pp. 2821-2832, 2016. Available at: https://doi.org/10.1016/j.aej.2016.07.012.

[25] J. Shubham and A. Mohad, "Structural analysis of seismic friction dampers," International Research Journal of Engineering and Technology, pp. 4348-4353, 2019. 
[26] S. Javadian, C. D. Treleaven, and I. C. Franks, "A case study for base isolation design: Spark data center facility-Auckland," presented at the NZSEE Conference, 2015.

[27] R. Mosbeh-Kaloop and J. Wan-Hu, "Seismic response of prediction of buildings with base isolation using advanced soft computing approaches," Advances in Material Science and Engineering, pp. 1-12, 2017.

[28] C. F. Ma, Y. H. Zhang, P. Tan, and F. L. Zhou, "Seismic response of base-isolated high-rise buildings under fully nonstationary excitation," Shock and Vibration, vol. 11, 2014.

[29] P. Pan, L. Ye, W. Shi, and H. Cao, "Engineering practice of seismic isolation and energy dissipation structures in China," Science China Technological Sciences, vol. 55, pp. 3036-3046, 2012. Available at: https://doi.org/10.1007/s11431-012-49226.

[30] T. Sunita and S. Ajay, "Effectiveness of base isolation technique and influence of isolator characteristics on response of a Base isolated building," American Journal of Engineering Research, vol. 5, pp. 198-209, 2016.

[31] A. M. Fabio, "Base-isolation system technique for the seismic protection of RC framed structures subjected near-fault ground motion," presented at the 13th World Conference on Earthquake Engineering, 2004.

[32] K. R. Lavanya and K. Manjunatha, "Comparative study on seismic effects of fluid viscous and visco-elastic damper in RC building," International Research Journal of Engineering and Technology (IRJET), vol. 3, pp. 138-144, 2016.

[33] K. Usha and H. R. Prabhakara, "Studies on effect of friction dampers on the seismic performance of RC multi-storey buildings," International Research Journal of Engineering and Technology, pp. 612-617, 2017.

[34] S. S. Sanghai and P. Y. Pawade, "Effect of Position and Number of Friction Dampers on seismic response of Frame," International Journal of Earth Sciences and Engineering, ISSN, 0974-5904, 2014.

[35] C. R. Sharmin, M. A. Rahman, M. J. Islam, and A. K. Das, "Effects of openings in shear wall on seismic response of structures," International Journal of Computer Applications, vol. 59, pp. 10-13, 2012.

[36] A. Anshul, S. Raghav, and D. Poonam, "Effect of different shear wall configurations on seismic response of moment resisting frame," European Scientific Journal, pp. 139-145, 2014.

[37] V. S. Gawady and V. S. Shingadi, "Seismic response of multi-storeyed reinforced concrete dual system with and without shear walls," International Journal of Science, Engineering and Technology Research, 2017.

[38] H. R. Varsha, "Comparative study of strength of RC shear wall at different location on Multi-storied residential building," International Journal of Civil Engineering Research, vol. 5, pp. 391-400, 2014.

[39] C. Balkaya and E. Kalkan, "Nonlinear seismic response evaluation of tunnel form building structures," Computers \& Structures, vol. 81, pp. 153-165, 2003. Available at: https://doi.org/10.1016/s0045-7949(02)00434-0.

[40] E. Kalkan and S. B. Yüksel, "Pros and cons of multistory RC tunnel-form (box-type) buildings," The Structural Design of Tall and Special Buildings, vol. 17, pp. 601-617, 2008.

[41] A. Tavafoghi and S. Eshghi, "Seismic behavior of tunnel form concrete building structures," presented at the The 14th World Conference on Earthquake Engineering October 12-17, 2008.

[42] S. Eshghi and A. Tavafoghi, "Seismic behaviour of tunnel form building structures: An experimental stud," in In Proceedings of the 15th World Conference on Earthquake Engineering, Lisbon, Portugal, 2012.

[43] N. A. Hamid and M. A. Masrom, "Seismic performance of wall-slab joints in industrialized building system (IBS) under outof-plane reversible cyclic loading," International Journal of Engineering and Technology, pp. 26-33, 2012.

[44] N. H. Hamid, S. M. Saleh, and S. A. Anuar, "Seismic performance of double-unit tunnel form building under in-plane lateral cyclic loading," Structures Under Shock and Impact, vol. 13, pp. 467-478, 2014.

[45] A. A. Shamilah, B. N. Faizah, A. S. Aweis, and A. R. Mustaqqim, "Seismic analysis of single unit tunnel form building subjected to out-of-plane lateral cyclic loading using ruaumoko 2D Programme," in Journal of Physics: Conference Series, 2020.

[46] N. H. Hamid and S. A. Anuar, "Modeling of a tunnel form building using ruaumoko 2D program, In advanced Engineering and Technology," in proceedings of the 2014 Annual Congress on Advanced Engineering and Technology, CAET, 2016, pp. $77-82$. 